\title{
Integration of dual fluidized bed steam gasification into the pulp and paper industry
}

\author{
Matthias Kuba ${ }^{1,2}$ (1) $\cdot$ Florian Benedikt ${ }^{2} \cdot$ Katharina Fürsatz $^{1,2} \cdot$ Josef Fuchs $^{2} \cdot$ Martin Demuth $^{3} \cdot$ Christian Aichernig $^{4}$. \\ Leo Arpa $^{5} \cdot$ Hermann Hofbauer ${ }^{1,2}$
}

Received: 3 September 2021 / Revised: 26 November 2021 / Accepted: 30 November 2021

(c) The Author(s) 2021

\begin{abstract}
The pulp and paper industry represents an industry sector which is characterised by its already high degree of sustainability. Biomass is a renewable input material, and typically highly developed recovery cycles minimise the loss of chemicals used in the pulping process. However, certain parts of the recovery cycle are still operated on fossil fuels. This study deals with the substitution of the fossil-based gaseous fuel with product gas from biomass gasification.

Gasification experiments have shown that bark available at pulp and paper mills is suitable to produce a product gas via dual fluidised bed steam gasification as a promising substitute for natural gas. Based on the comparison of process layouts regarding the separation of non-process elements, separation efficiency is derived for different setups. To ensure operational security of the chemical recovery cycle, comprehensive gas cleaning including heat exchangers, a particle filter, and a liquid scrubber unit is advised. The gas flow of fuel gas into the gas burner is increased as the heating value of the product gas is accordingly lower in comparison to natural gas. Furthermore, adaptions of the gas burner might be necessary to address the earlier ignition of the $\mathrm{H}_{2}$-rich product gas compared to natural gas.
\end{abstract}

Keywords Gasification · Product gas · Pulp and paper making · Gas burner · Oxygen-enhanced combustion

\section{Introduction}

The pulp and paper industry is characterised as one of the furthest developed biorefinery processes. It has been advanced for more than 100 years. While at the beginning of this long-term optimisation process, economic reasons were dominant; ecologic sustainability has become the main driver for the innovation process $[1,2]$.

Matthias Kuba

matthias.kuba@best-research.eu

1 BEST - Bioenergy and Sustainable Technologies GmbH, Inffeldgasse 21b, $8010 \mathrm{Graz}$, Austria

2 TU Wien, Institute of Chemical, Environmental and Bioscience Engineering, Getreidemarkt 9/166, 1060 Vienna, Austria

3 Messer Austria GmbH, Industriestraße 5, 2352 Gumpoldskirchen, Austria

4 Aichernig Engineering GmbH, Nordbahnstrasse 36/3/Top 2.5, 1020 Vienna, Austria

5 Mondi AG, Marxergasse 4A, 1030 Vienna, Austria
The pulp and paper industry has experienced significant progress with the development of the kraft process. It established the industrial production of paper of high tensile strength. This was based on the treatment of wood chips with sodium hydroxide and sodium sulphide (in former times sodium sulphate was used) in hot water. This cooking mixture is referred to as white liquor. Its purpose is to break the chemical bonds between lignin, hemicellulose, and cellulose. During this development, great efforts in the development of the pulp and paper process based on the kraft process have been made. Two key points were central in this development. Firstly, the closure of the internal processes and subsequently the maximisation of the recovery of chemicals [3]. To achieve this ambitious goal, the introduction of the recovery boiler in the chemical recovery cycle was one of the central developments [4]. The subsequent closure of internal processes increased the efficiency of the mills and the necessity for makeup chemicals was decreased significantly. From 1919 to 2020, the amount of $\mathrm{Na}_{2} \mathrm{SO}_{4}$ losses was reduced from approx. 150 to approx. $17 \mathrm{~kg} \mathrm{Na}_{2} \mathrm{SO}_{4}$ per ton of pulp [1]. 
Table 1 Negative effects from the accumulation of NPE in chemical recovery processes with a high degree of closure [2]

\begin{tabular}{ll}
\hline Negative effects & Elements \\
\hline Scaling, deposits & $\mathrm{Al}, \mathrm{Si}, \mathrm{Ca}, \mathrm{Ba}$ \\
Plugging in the recovery boiler & $\mathrm{K}, \mathrm{Cl}$ \\
Corrosion & $\mathrm{K}, \mathrm{Cl}$ \\
Inert compounds in the lime cycle & $\mathrm{P}, \mathrm{Mg}, \mathrm{Al},(\mathrm{Si})$ \\
Disturbances in the hydrogen peroxide bleaching & $\mathrm{Mn}, \mathrm{Fe}, \mathrm{Cu}$ \\
Environment (air and water) & $\mathrm{N}, \mathrm{P}, \mathrm{Cd}, \mathrm{Pb}$, and \\
& other heavy \\
& metals \\
\hline
\end{tabular}

However, while the chemical losses were minimised and the process efficiency increased, the closure of the internal processes also led to additional problems during long-term operation. Non-process elements (NPE), a term used for the inorganic components of biomass that do not serve a purpose in the paper making process, are introduced into the mill externally by wood. These NPE are separated to a large extent from the fibres during the pulping process as air or water contaminants or as solid waste. Due to increased closure of the internal processes, these NPE accumulate over time and result in a variety of problems, which are summarised in Table $1[2,5]$.

These issues have been solved to a certain extent over the years by adding separation equipment, referred to as kidneys in the pulp and paper process [6]. Nevertheless, especially the input of inorganic compounds into the lime cycle can still be an issue leading to ring-type deposit build-up in the lime kiln or quality decrease of the lime based on the formation of calcium phosphate [7-9]. The solubility of calcium phosphate is lower in white liquor than it is in green liquor which results in precipitation during the causticising process and subsequent accumulation in the lime cycle. This leads to the high sensitivity of closed pulp and paper processes to the introduction of NPE $[1,2]$.

The pulp and paper industry is already characterised by its high degree of sustainability. Biomass as input is renewable, and if the overall process layout is designed sustainably, the recovery cycle minimises the loss of chemicals used in the pulping process $[10,11]$. However, the lime cycle which is part of the causticising process is still dependent on fossil fuel for the operation of the lime kiln. Typically, lime kilns in pulp and paper mills are fired by natural gas or a $\mathrm{CH}_{4}$-rich off-gas from a fossil-based industry nearby. To transform the pulp and paper industry into an even more sustainable industry sector, the substitution of fossil-based gaseous fuel is necessary.

Steam gasification of biomass is a possibility to produce a burnable gas of medium calorific value (12-14 MJ/kg) which could be used to operate the lime kiln [12]. Gasification of biomass has been investigated for different applications and extensive experience from both a research and also a commercial perspective is available $[13,14]$. A DFB steam gasification process was developed at TU Wien [15]. The principle underpinning this process is the spatial separation of endothermic gasification and exothermic combustion. The heat necessary for devolatilisation and gasification is provided by circulating the bed material from the combustion to the gasification reactor. The natural mineral olivine is used as bed material which also acts as a catalyst for the ongoing reactions in the gasification reactor. Steam is used as a fluidising agent for the bubbling bed in the gasification reactor. Fast fluidisation in the combustion reactor $(\mathrm{CR})$ is realised by using air. Part of the devolatilised biomass or biomass char is combusted to provide the heat necessary for gasification [16]. More details on the process will be given in the section Materials and Methods.

Inorganic material plays a key role in the successful operation of DFB steam gasification. Inorganic components inside the gasification reactor (GR) originate either from the biogenic feedstock or are introduced as bed material or as additives. The interactions between the inorganic components influence the ash transformation chemistry which consequently influences long-term operation. Boström et al. published an article in which the basic foundation of main ash transformation reactions for the thermal conversion of woody biomass are presented [17]. Of special interest to steam gasification is a phenomenon referred to as ash layer formation on bed material particles. Interaction of biomass ash and/or inorganic additives such as limestone leads to the formation of bed material particle layers, which have been observed to enhance the catalytic activity towards tar reduction in gasification [18-21]. Investigations on a 100$\mathrm{kW}$ DFB steam gasification pilot plant confirmed the catalytic activity of calcium oxide as bed material regarding tar reduction [16]. The catalytic activity has been correlated to the enrichment of Ca on the particles' surfaces [22]. Thus, the introduction of discharged lime from the lime cycle into the gasification reactor could lead to further closure of the internal process cycles while positively promoting tar reduction [23].

The aim of the present study is the integration of DFB steam gasification into pulp and paper mills. Integrating gasification into pulp and paper mills has been evaluated in different configurations before, spanning from internal electricity production to more advanced biorefinery concepts $[12,24]$. An intensive study shows the state-of-the-art for the integration of DFB gasification in industry sectors using the product gas as syngas for example. SNG production or as direct fuel gas which can be utilised in e.g. lime kilns [25]. In Sweden, a strong focus has been put on the gasification of black liquor [26-28]. In such a concept, the integration of gasification occurs directly in the chemical recovery cycle of the paper mill [28]. Black liquor is resulting from the kraft pulping process. Currently, it is burned 


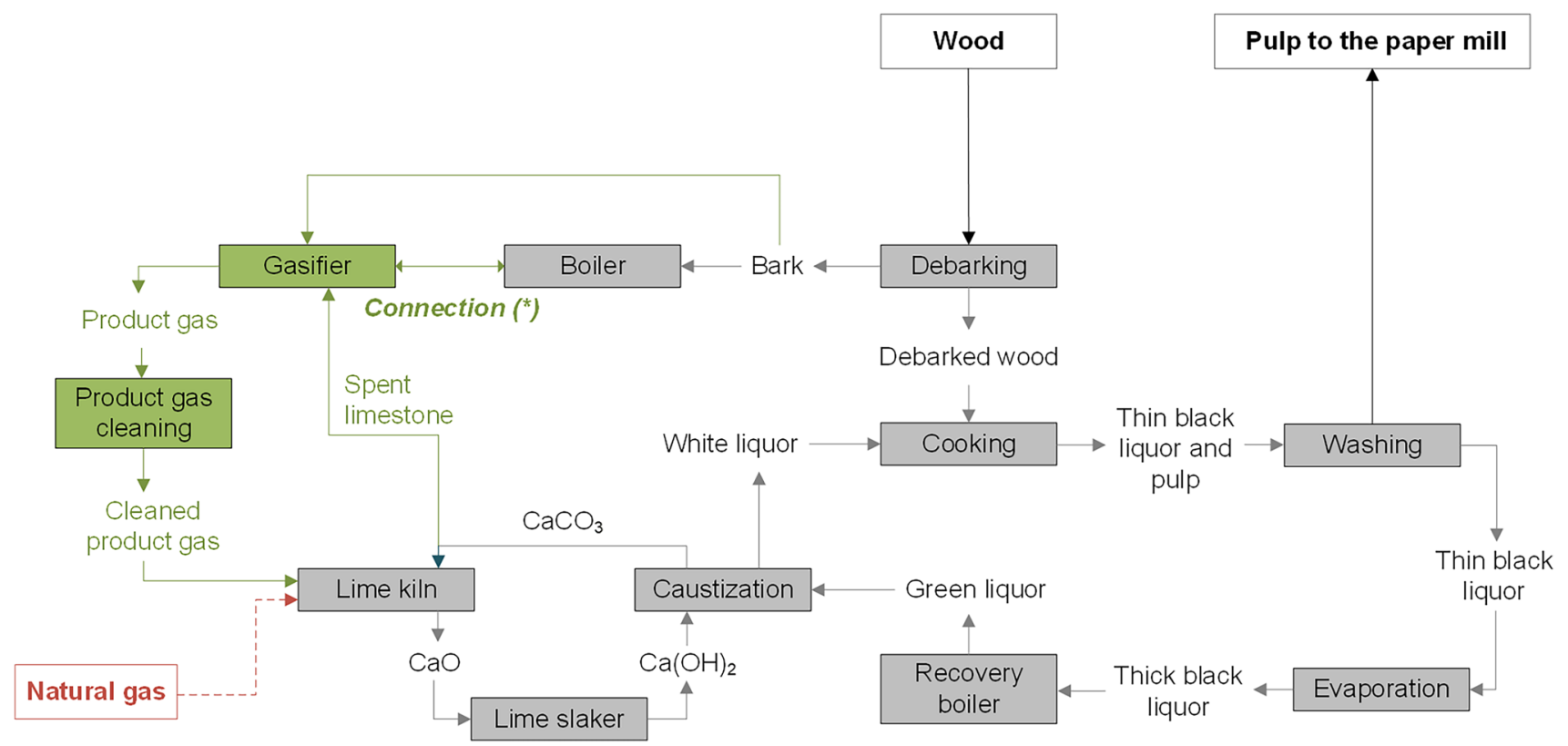

Fig. 1 Overall integration of steam gasification into the chemical recovery process of a modern pulp and paper mill as suggested in this study

in a boiler for the production of steam and electricity. Typically, both steam and electricity are used internally within the pulp mill. However, excess electricity can also be sold to the grid to improve the economic performance of the process [26, 29, 30]. Using black liquor in gasification could lead to the production of products of higher value but would significantly interfere with the existing infrastructure within the mill [31]. The present research article does not deal with black liquor as input material; however, it would be a valid option to expand the research idea also to black liquor as feedstock.

How to achieve satisfactory gas cleaning to avoid the accumulation of NPE in such a closed process is of high importance and will be addressed within this work. In this regard, different process designs concerning the necessary gas cleaning will be evaluated and discussed. Thus, the role of NPE both inside the gasification reactor and also their separation downstream will be discussed based on the known sensitivity of the lime cycle to their introduction.

Finally, burning the product gas from steam gasification in gas burners will be evaluated in comparison to natural gas to evaluate the substitution of fossil-based $\mathrm{CH}_{4}$-rich gas.

\section{Materials and methods}

\subsection{Integration of gasification into pulp and paper mills}

Figure 1 shows the suggested overall integration of steam gasification into the causticising process of a modern pulp and paper mill proposed in the present study. Here, the focus lies on the gasification of bark rather than black liquor.

Already established process units of a modern pulp and paper mill are indicated in grey colour, whereas the proposed integration of gasification is highlighted in green colour. The proposed integration leads to the production of sustainable gaseous fuel for the lime kiln, which further results in connecting the already existing bark boiler with the lime cycle. Therefore, the recovery of green liquor into white liquor shall be transformed into a renewablebased process. This is achieved by adding a gasification unit to the already established bark boiler and thus, using an already existing circulating fluidised bed (CFB) combustion reactor for the DFB gasification process. This has already been proposed by Thunman et al. [32] showing the potential in the pulp and paper industry in Sweden. DFB gasification using bark as fuel has been investigated from laboratory to industrial scale [33-35]. Figure 1 also shows the possibility to introduce discharged limestone from the lime cycle into the gasification reactor for enhancing the catalytic gasification activity.

\subsection{Steam gasification in a 100-kW th $D F B$ pilot plant}

Figure 2 shows a simplified scheme of the DFB steam gasification process. Fuel is added to the GR, where it is converted into PG with steam as the gasification agent. The char remaining after gasification is transported to the $\mathrm{CR}$ with the bed material. Inside the CR, char combustion occurs, 
Fig. 2 Scheme of the advanced $100-\mathrm{kW}_{\text {th }}$ DFB reactor system at TU Wien marked with sampling points and temperature measurement points [33]

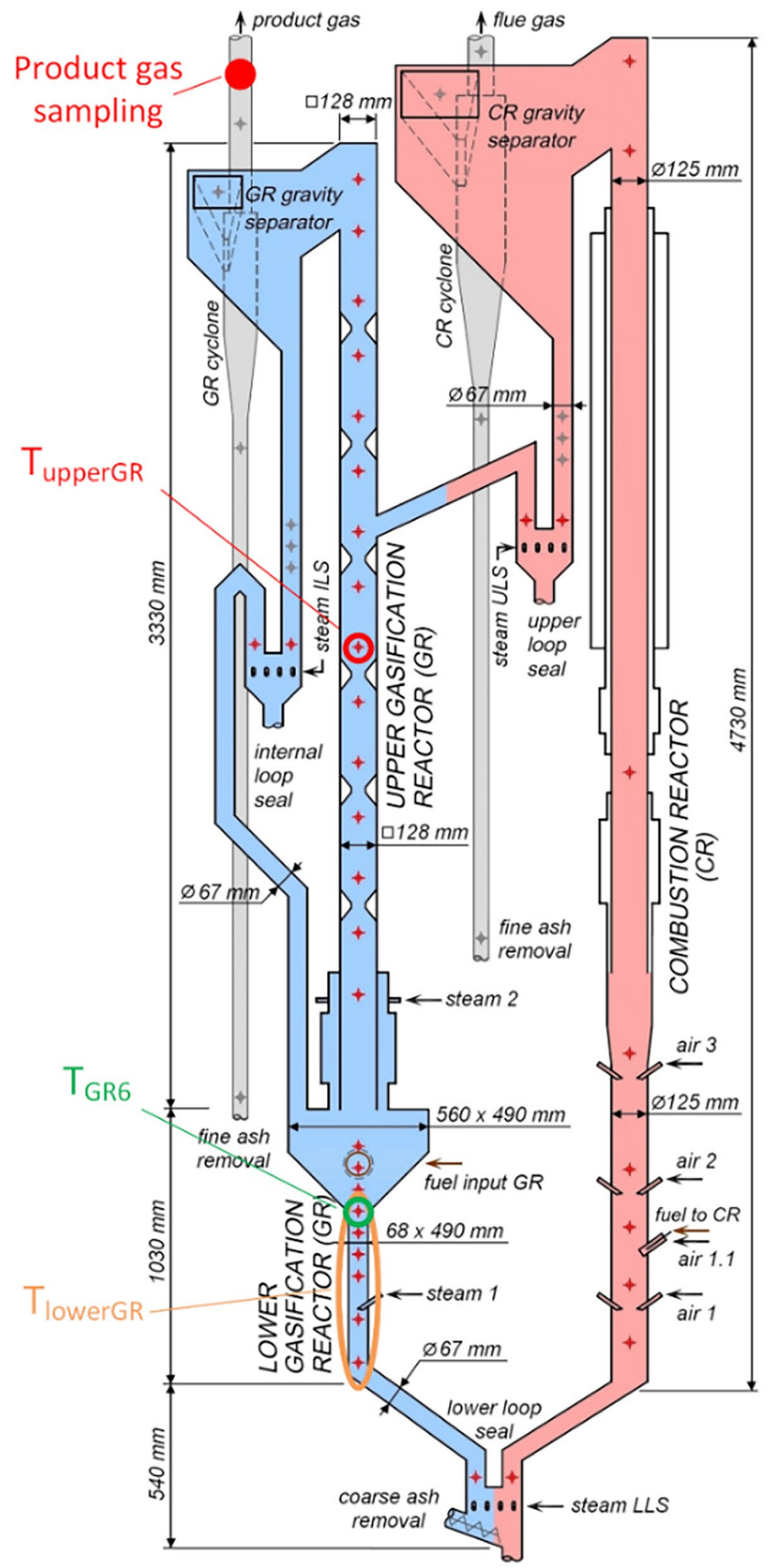

$T_{\text {upperGR }}$ : Representatitive temperature of upper GR for WGS deviation calculation

$T_{\text {lowerGR: }}$ Average temperature of bubbling bed in lower GR

$T_{G R 6}$ : Temperature in bubbling bed close to fuel input 
heating up the bed material up to 950 to $1000{ }^{\circ} \mathrm{C}$. The hotter bed material is transferred back to the GR, providing the gasification with the heat needed for the endothermal gasification reactions.

The advanced $100-\mathrm{kW}_{\text {th }}$ DFB reactor system has two GRs, a lower and an upper GR. The lower GR is a bubbling fluidised bed fluidised with steam. The upper GR has several geometrical constrictions to create turbulent zones, increasing the contact between the hotbed material coming from the CR and the gas produced in the lower GR. Gravity separators are used instead of cyclones to allow for the use of softer bed materials like limestone $[16,33,36]$.

For the heating-up procedure of the $100-\mathrm{kW}_{\text {th }}$ pilot plant, both reactors are operated with air. The plant is heated up electrically until $400{ }^{\circ} \mathrm{C}$ are reached. From that point on, wood pellets in the GR and heating oil in the $\mathrm{CR}$ are used to heat the plant further to approx. $850{ }^{\circ} \mathrm{C}$. After this temperature is reached, the fluidisation of the GR is switched to steam and direct electrical heating of the plant is turned off. The oil fed to the Cr during start-up is now reduced to the amount which is necessary to keep the desired operating temperature. Throughout the pilot plant operation, input steam and air are further heated electrically which is provided in industrial applications through internal process heat utilisation [37, 38]. Typically, the plant is operated with wood pellets until a stable operation is reached. Afterwards, the experiments with the planned fuels, in this case, bark from a pulp and paper mill in Austria started.

All relevant temperatures, pressures, and flow rates were recorded continuously. The product gas composition $\left(\mathrm{H}_{2}, \mathrm{CO}, \mathrm{CO}_{2}, \mathrm{CH}_{4}\right)$ was measured continuously with a Rosemount NGA 2000. $\mathrm{C}_{2} \mathrm{H}_{4}, \mathrm{C}_{2} \mathrm{H}_{6}, \mathrm{C}_{3} \mathrm{H}_{8}$, and $\mathrm{N}_{2}$ were measured every $12-15 \mathrm{~min}$ by a PerkinElmer ARNEL - Clarus 500 Gas Chromatograph. The product gas was sampled from the point indicated in Fig. 2. Previous research has shown that the counter-current column atop the lower GR further increases the observed catalytic activity by increasing $\mathrm{H}_{2}$ yields and reducing the product gas tar content [39].

Tar samples were collected discontinuously by isokinetically taking samples with impinger bottles filled with toluene to condense and dissolve all condensable hydrocarbons. The mass of tar left after vacuum evaporation of the solvent is characterised as gravimetric tar. Medium molecular weight tars were analysed by a gas chromatograph coupled with mass spectroscopy (GCMS) giving the GCMS tars. All the tar contents given exclude benzene, toluene, ethylbenzene, and xylene due to the sampling procedure. The tar dew points of the detected GCMS tar compounds were calculated with the calculation tool from ECN/TNO. ${ }^{1}$
Table 2 Fuel characteristics of bark used for gasification experiments

\begin{tabular}{lll}
\hline Parameter & Unit & Value \\
\hline Water content & w\% & 11.5 \\
Volatiles & w\%, dry & 72.3 \\
Lower heating value (dry) & MJ/kg, dry & 18,052 \\
Lower heating value & MJ/kg & 15,695 \\
Ash content & w\%, dry & 7 \\
Carbon $(\mathrm{C})$ & w\%, dry & 48.66 \\
Hydrogen $(\mathrm{H})$ & w\%, dry & 5.56 \\
Oxygen $(\mathrm{O})$ & w\%, dry & 38.4 \\
Nitrogen $(\mathrm{N})$ & w\%, dry & 0.318 \\
Sulphur $(\mathrm{S})$ & w\%, dry & 0.0491 \\
Chloride $(\mathrm{Cl})$ & w\%, dry & 0.049 \\
\hline
\end{tabular}

This is an important value regarding the fouling potential in the downstream equipment of the gasifier. A more detailed description of the measurements performed can be found in the work by Mauerhofer et al. [39].

\subsection{Fuel and bed materials used for gasification experiments}

The fuel used in all experimental investigations was bark provided from the pulp and paper producer Mondi AG. Analysis of the fuel was performed by the in-house laboratory of BEST-Bioenergy and Sustainable Technologies using standardised fuel characterisation. Table 2 shows the fuel analysis of the bark.

Experiments in the $100-\mathrm{kW}_{\text {th }}$ DFB pilot plant were performed using different types of bed material. Olivine, a magnesium iron silicate with the formula $\left(\mathrm{Mg}^{2+}\right.$, $\left.\mathrm{Fe}^{2+}\right)_{2} \mathrm{SiO}_{4}$, which has been typically used in industrial DFB gasification plants, was used to establish a benchmark. Olivine is also a mineral that is sometimes used in fluidised bed combustion boilers in the industry. Quartz was used as bed material to investigate its suitability in DFB steam gasification, as most industrial fluidised bed combustion boilers operate on this material. Due to the aim of this work to integrate steam gasification into already existing infrastructure in pulp and paper mills, quartz is the most likely bed material already in use. Table 3 shows the elemental composition (expressed as oxides), the hardness, and particle density of the used quartz material. Based on the knowledge of the enhancement of the catalytic activity due to $\mathrm{Ca}$ enrichment, a benchmark using pure limestone as bed material was established as well.

$\overline{1}$ https://www.thersites.nl/completemodel.aspx 
Table 3 Elemental composition (expressed as oxides), the hardness, and particle density of the used bed materials

\begin{tabular}{|c|c|c|c|c|}
\hline Parameter & Unit & Limestone & Olivine & Quartz \\
\hline $\mathrm{CaCO}_{3}$ & wt. $\%$ & $95-97$ & $<0.1$ & - \\
\hline $\mathrm{CaO}$ & wt. $\%$ & - & $<0.4$ & - \\
\hline $\mathrm{MgO}$ & wt. $\%$ & - & $48-50$ & - \\
\hline $\mathrm{MgCO}_{3}$ & wt.\% & $1.5-4.0$ & - & - \\
\hline $\mathrm{SiO}_{2}$ & wt.\% & $0.4-0.6$ & $39-42$ & 99.8 \\
\hline $\mathrm{Al}_{2} \mathrm{O}_{3}$ & wt.\% & $0.2-0.4$ & - & 0.1 \\
\hline $\mathrm{Fe}_{2} \mathrm{O}_{3}$ & wt. $\%$ & $0.1-0.3$ & $8.0-10.5$ & 0.04 \\
\hline $\mathrm{K}_{2} \mathrm{O}$ & wt.\% & - & - & - \\
\hline $\mathrm{Na}_{2} \mathrm{O}$ & wt.\% & - & - & - \\
\hline Hardness & Mohs & 3 & $6-7$ & 7 \\
\hline Particle density & $\mathrm{kg} / \mathrm{m}^{3}$ & $\sim 2650$ & $\sim 2850$ & $\sim 2650$ \\
\hline $\begin{array}{l}\text { Particle density (after } \\
\text { full calcination) }\end{array}$ & $\mathrm{kg} / \mathrm{m}^{3}$ & $\sim 1500$ & - & - \\
\hline
\end{tabular}

\subsection{IPSEpro process simulation to calculate mass and energy balances of the overall process}

By using the process simulation software IPSEpro, mass and energy balances can be calculated based on process data that was obtained during gasification test runs. IPSEpro is an equation-oriented process simulation software. It originates from the power plant sector and offers the user stationary process simulation. Furthermore, IPSEpro enables validating measured experimental data of overdetermined balancing systems. The validation of raw data uses the software module PSValidate of the IPSEpro programme package. The process model is solved with a data adjustment algorithm that minimises the weighted sum of the squares of the differences between redundant measured values. For the validation of each presented test run in the $100-\mathrm{kW}_{\text {th }}$ pilot plant at steady-state conditions, a system model with more than 8500 variables must be solved. Thereby, several redundant values are defined with a permitted deviation for each value according to its expected measurement inaccuracy. Weber et al. [40] explain a similar validation approach with IPSEpro in more detail. Pröll and Hofbauer [41] developed a comprehensive model library for biomass gasification. It enables the user to calculate important values via mass and energy balances that cannot be measured directly.

By the use of process simulation, the following key performance indicators (KPI) are calculated, which were also used in previous work on the advanced DFB steam gasification pilot plant by Benedikt et al. [16]. The steam to fuel ratio $\varphi_{\mathrm{SF}}(-)$ yields the ratio of the amount of total steam from fluidisation and fuel water to that of dry and ash-free fuel fed into the GR, as given by Eq. 1. $\dot{\mathrm{m}}_{\text {steam }, G R}(\mathrm{~kg} / \mathrm{s})$ is the mass flow of steam into the GR, $\dot{m}_{\mathrm{H} 2 \mathrm{O}, \mathrm{GR}, \mathrm{fuel}}(\mathrm{kg} / \mathrm{s})$ is the mass flow of water into the GR with the fuel, and $\dot{m}_{\mathrm{GR} \text {,fuel,daf }}$ $(\mathrm{kg} / \mathrm{s})$ stands for the mass flow of the dry and ash-free fuel into the GR. The steam to carbon ratio $\varphi_{\mathrm{SC}}(-)$ is given in Eq. 2. It is used to enable a comparison between test runs of fuel types with different carbon content. Here, $\dot{\mathrm{m}}_{\mathrm{C}, \mathrm{GR} \text {,fuel }}$ $(\mathrm{kg} / \mathrm{s})$ is the carbon mass flow with the fuel into the GR. The product gas yield PGY $\left(\mathrm{m}^{3} / \mathrm{kg}\right)$ is presented in Eq. 3 and gives the ratio between the dry product gas volume flow to that of the dry and ash-free mass flow of fuel introduced into the GR. $\dot{\mathrm{V}}_{\mathrm{PG}}\left(\mathrm{m}^{3} / \mathrm{s}\right)$ stands for the dry product gas flow out of the GR. The steam-related water conversion $X_{\mathrm{H} 2 \mathrm{O}}(-)$ shows the relation of water consumed and water introduced into the GR and is depicted in Eq. 4, whereas $\dot{\mathrm{m}}_{\mathrm{H} 2 \mathrm{O}, \mathrm{PG}}(\mathrm{kg} / \mathrm{s})$ is the mass flow of water in the product gas. Equation 5 gives the cold gas efficiency (CGE) $\eta_{\mathrm{CG}}$ (\%), which describes the ratio of chemical energy in the product gas to the chemical energy in the fuel that is fed into the GR, based on the lower heating value. $\eta_{\mathrm{CG}}$ is a pure chemical energy ratio. In this equation, $\mathrm{LHV}_{\mathrm{PG}}(\mathrm{MJ} /$ $\mathrm{m}^{3}$ ) denotes the lower heating value of the dry product gas and $\mathrm{LHV}_{\mathrm{GR}, \text { fuel }}(\mathrm{MJ} / \mathrm{kg})$ the lower heating value of the fuel into the $\mathrm{GR} ; \dot{\mathrm{m}}_{\mathrm{CR} \text {,fuel }}(\mathrm{kg} / \mathrm{s})$ and $\mathrm{LHV}_{\mathrm{CR} \text {,fuel }}(\mathrm{MJ} / \mathrm{kg})$ are the respective values in case of fuel feeding into the $\mathrm{CR}$. Equation 6 describes the overall cold gas efficiency (CGEo) $\eta_{\mathrm{CG}, \mathrm{o}}(\%)$, which is an extension of the cold gas efficiency. $\eta_{\mathrm{CG}, \mathrm{o}}$ comprises the possibility to compare scientific test results from plants with very high specific heat losses with that of industrial-sized plants having very low specific heat losses $\dot{\mathrm{Q}}_{\text {loss }}(\mathrm{MJ})$. The mean radiative heat loss of the insulated $100-\mathrm{kW}$ stainless steel pilot plant for a typical test run is ca. $20-30 \mathrm{~kW}$ (20-30\% of the GR fuel input power). An industrial-sized plant with $15 \mathrm{MW}$ fuel power typically has a ten times lower specific radiative heat loss of $2-4 \%$ over the refractory-lined and good insulated fluidised bed reactor system. Thus, $\eta_{\mathrm{CG}, \mathrm{o}}$ also considers the fuel fed into the GR as well as the relatively high specific radiating heat losses of the $100-\mathrm{kW}$ pilot plant, and therefore, indicates the potential value of the overall efficiency with zero radiative heat losses.

$$
\begin{aligned}
& \varphi_{S F}=\frac{\dot{\mathrm{m}}_{\text {steam,GR }}+\dot{\mathrm{m}}_{\mathrm{H} 2 \mathrm{O}, \mathrm{GR}, \text { fuel }}}{\dot{\mathrm{m}}_{\mathrm{GR}, \text { fuel,daf }}} \\
& \varphi_{\mathrm{SC}}=\frac{\dot{\mathrm{m}}_{\text {steam,GR }}+\dot{\mathrm{m}}_{\mathrm{H} 2 \mathrm{O}, \mathrm{GR}, \text { fuel }}}{\dot{\mathrm{m}}_{\mathrm{C}, \mathrm{GR}, \text { fuel }}} \\
& \text { PGY }=\frac{\dot{\mathrm{V}}_{\mathrm{PG}}}{\dot{\mathrm{m}}_{\mathrm{GR}, \text { fuel,daf }}}
\end{aligned}
$$


Table 4 Main operation parameters for gasification test runs with a variation of bed material with limestone and olivine

\begin{tabular}{llllllll}
\hline Fuel & - & SW & SW & SW & BA & BA & BA \\
\hline Bed material & wt.\% & $100 \%$ OL & $\begin{array}{l}90 \% \text { QS } \\
10 \% \text { LS }\end{array}$ & $100 \%$ LS & $100 \%$ OL & $90 \%$ QS & $100 \%$ LS \\
& & & & & $10 \%$ LS & \\
Fuel power GR & $\mathrm{kW}$ & 100.3 & 100.8 & 100.9 & 95.6 & 96.0 & 101.5 \\
Fuel power CR & $\mathrm{kW}$ & 66.9 & 64.9 & 52.1 & 31.8 & 71.1 & 56.4 \\
Temperature lower $\mathrm{GR}^{1}$ & ${ }^{\circ} \mathrm{C}$ & 759 & 790 & 789 & 776 & 820 & 761 \\
Temperature upper $\mathrm{GR}^{1}$ & ${ }^{\circ} \mathrm{C}$ & 893 & 947 & 991 & 899 & 955 & 965 \\
Temperature CR & ${ }^{\circ} \mathrm{C}$ & 968 & 1008 & 1031 & 946 & 1016 & 995 \\
S/F ratio & - & 0.9 & 0.9 & 0.7 & 0.8 & 1.0 & 1.0 \\
S/C ratio & - & 1.8 & 1.7 & 1.4 & 1.6 & 2.0 & 1.6 \\
$X_{\mathrm{H} 20}$ & - & 0.26 & 0.31 & 0.36 & 0.19 & 0.42 & 0.34 \\
PGY & $\mathrm{Nm}^{3}{ }_{\mathrm{db}} / \mathrm{kg}_{\mathrm{daf}}$ & 1.36 & 1.41 & 1.4 & 1.14 & 1.76 & 1.4 \\
CGE,o & $\%$ & 74 & 71 & 73 & 67 & 73 & 74 \\
PG LHV & ${\mathrm{MJ} / \mathrm{Nm}^{3}{ }_{\mathrm{db}}}$ & 13.2 & 12.3 & 11.3 & 11.76 & 11.4 & 10.9 \\
\hline
\end{tabular}

$\mathrm{X}_{\mathrm{H} 2 \mathrm{O}}=\frac{\dot{\mathrm{m}}_{\text {steam,GR }}+\dot{\mathrm{m}}_{\mathrm{H} 2 \mathrm{O}, \mathrm{GR}, \mathrm{fuel}}-\dot{\mathrm{m}}_{\mathrm{H} 2 \mathrm{O}, \mathrm{PG}}}{\dot{\mathrm{m}}_{\text {steam,GR }}+\dot{\mathrm{m}}_{\mathrm{H} 2 \mathrm{O}, \mathrm{GR}, \text { fuel }}}$

$\eta_{\mathrm{CG}}=\frac{\dot{\mathrm{V}}_{\mathrm{PG}} \times \mathrm{LHV}_{\mathrm{PG}}}{\dot{\mathrm{m}}_{\mathrm{GR}, \text { fuel }} \times \mathrm{LHV}_{\mathrm{GR}, \text { fuel }}} \cdot 100$

$\eta_{\mathrm{CG}, \mathrm{o}}=\frac{\dot{\mathrm{V}}_{\mathrm{PG}} \times \mathrm{LHV}_{\mathrm{PG}}}{\dot{\mathrm{m}}_{\mathrm{GR}, \text { fuel }} \times \mathrm{LHV}_{\mathrm{GR}, \text { fuel }}+\dot{\mathrm{m}}_{\mathrm{CR} \text {,fuel }} \times \mathrm{LHV}_{\mathrm{CR}, \text { fuel }}-\dot{\mathrm{Q}}_{\text {loss }}} \cdot 100$

The validated data and calculated KPI from the $100-\mathrm{kW}_{\text {th }}$ pilot plant operation together with experience from largescale simulation work [38] offer the possibility to scale up the process by means of process simulation.

\subsection{Gas burner tests}

Gas burner tests were performed at the research centre for high-temperature processes from the industrial gas specialist Messer Austria GmbH. ${ }^{2}$ The combustion behaviour of a simplified product gas mixture $\left(11.9 \mathrm{Vol} \% \mathrm{CH}_{4}, 16.7 \mathrm{Vol} \%\right.$ $\mathrm{CO}, 31.6 \mathrm{Vol} \% \mathrm{CO}_{2}, 39.8 \mathrm{Vol} \% \mathrm{H}_{2}$ ) was tested both in a free stand and a combustion chamber. The product gas composition was chosen to represent a simplified typical product gas from steam gasification. The steam content, which is to be expected after liquid scrubbing, would be approx. 6-8 Vol\%. The impact of the steam was not included in this first study; therefore, the expected steam content was included in the inert gas $\mathrm{CO}_{2}$.

Experiments were performed with a $250-\mathrm{kW}$ nominal power test burner at 100 - and $200-\mathrm{kW}$ gas input with product gas as well as natural gas as a benchmark at the free stand

\footnotetext{
$\overline{2}$ https://www.messer.at/
}

and $102 \mathrm{~kW}$ input in the combustion chamber at the research centre for high-temperature processes from the industrial gas supplier Messer. At the free stand, the flame length was measured and the maximal temperatures on the burner, as well as their position (end or middle section of the burner), were determined. During the burner chamber experiments, several ratios of oxygen enrichment of combustion air were performed during product gas combustion and the temperatures measured on the chamber walls were compared to natural gas combustion with air. The burner chamber is described in more detail in previous publications [42].

\section{Results and discussion}

In the following, results from experimental investigations, calculation of mass and energy balances, and gas burner tests will be presented and discussed.

\subsection{Steam gasification of bark using different bed materials in the advanced $100-\mathrm{kW}_{\text {th }}$ pilot plant}

Results with the standard fuel softwood (SW) are presented as a comparison to bark (BA). Three different bed materials are applied olivine (OL), quartz sand (QS), and limestone (LS). The main operating parameters for the test runs together with several KPI are presented in Table 4.

${ }^{1}$ Location of measurement points see Fig. 2

Figure 3 and Fig. 4 show the main dry product gas composition as well as tar content and tar dew point comparing the three different bed materials and bed material mixtures, respectively. For all six experiments, comparable product gas qualities could be achieved. During the experiments, an already reported correlation between increasing content of limestone and increasing $\mathrm{H}_{2}$ content could be verified. For the case of softwood as input, the $\mathrm{H}_{2}$ content could 


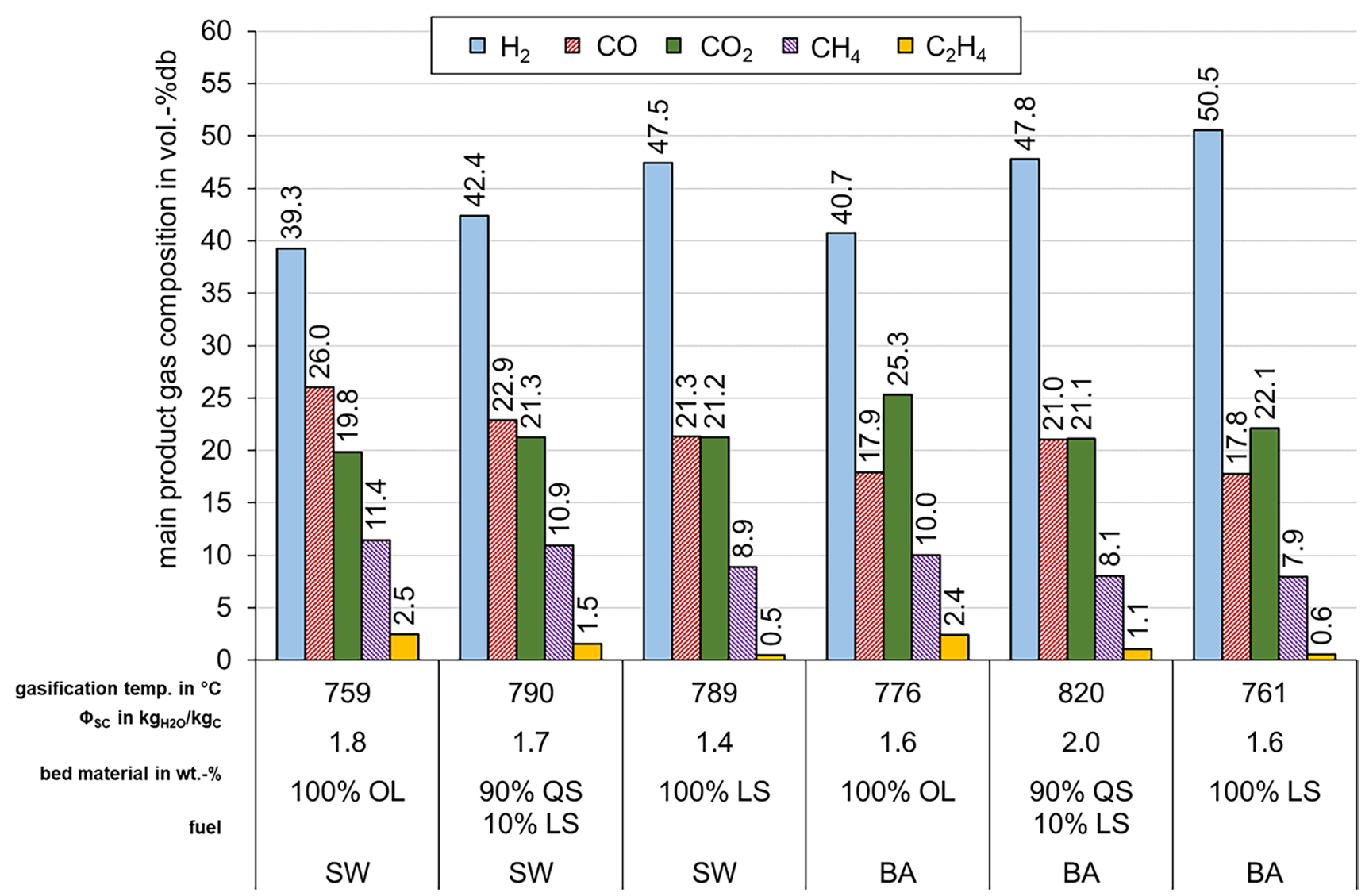

Fig. 3 Product gas composition using three different bed materials with softwood as standard fuel and bark

be increased from approx. 39.3 with olivine to approx. $47.5 \mathrm{Vol}_{\mathrm{db}} \%$ when limestone was used as bed material. The experiment with quartz sand and $10 \%$ limestone also shows the impact of using discharged limestone from the lime cycle of the pulp and paper mills as an additive in the gasification reactor (Fig. 3). This is also supported by the results of the tar measurements. The addition of limestone significantly reduces the tar content in the product gas and also, subsequently, reduces the tar dew point in comparison to the experiment with olivine as bed material (Fig. 4). It is especially noteworthy to mention that the GC-MS tar content (excl. BTEX) was $7.7 \mathrm{~g} / \mathrm{Nm}^{3}{ }_{\mathrm{db}}$ in the experiment with bark using quartz with $10 \mathrm{wt} . \%$ limestone in comparison to $18.1 \mathrm{~g} / \mathrm{Nm}_{\mathrm{db}}^{3}$ in the experiment with olivine. Similar findings were gained for the gravimetric tar content with a decrease from 5.3 using olivine to $1.7 \mathrm{~g} / \mathrm{Nm}^{3}{ }_{\mathrm{db}}$ using quartz with $10 \mathrm{wt} \%$ limestone as bed material. Quartz is a non-catalytic material in comparison to olivine after activation by ash layers, which has been reported to show a certain extent of catalytic activity towards tar reduction. Therefore, it is noteworthy that the addition of limestone to the quartz bed material significantly influences the tar reduction in the reactor and subsequently improves the product gas quality.

In summary, the results from the gasification experiments in the 100-kW advanced DFB pilot plant have shown that bark from pulp and paper mills can be used to obtain a valuable product gas as a secondary energy carrier, which is a potential substitute for fossil-derived combustible gases. If quartz sand is used as bed material, the addition of discharged limestone from the lime cycle leads to an enhancement of the catalytic activity resulting in an improved product gas quality concerning the main product gas composition as well as the tar content. This increase of the catalytic activity is due to the Ca enrichment in the reactor, which also further leads to an increase of the $\mathrm{Ca}$ availability during ash layer formation on bed particles. Subsequently, this results in a long-term availability of the catalytic effect in the reactor, as reported in previous publications [23, 37, 43].

\subsection{Gas cleaning and its impact on the separation of non-process elements}

In the following, different gas cleaning setups for the separation of NPE from the product gas of bark gasification are 


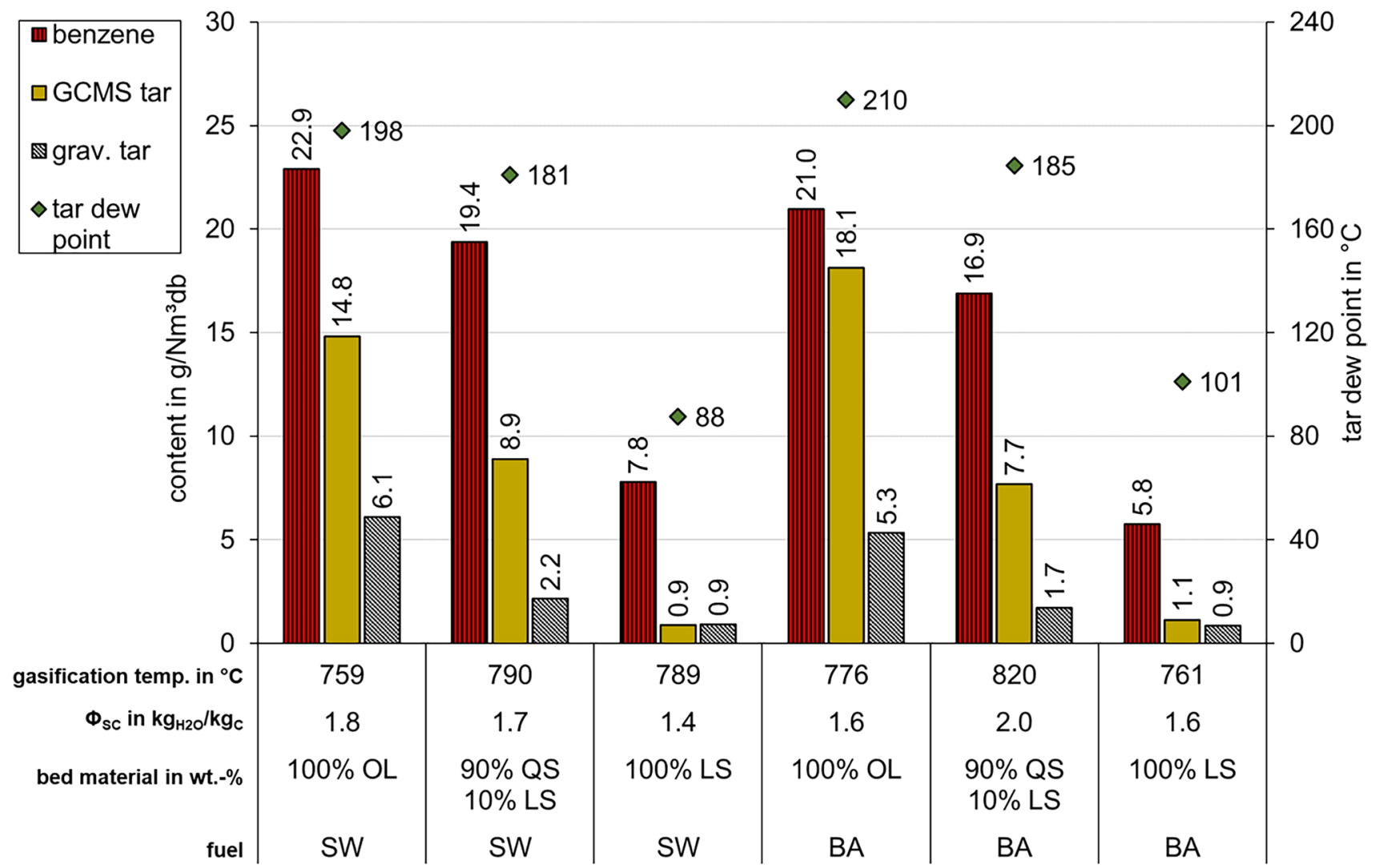

Fig. 4 Benzene, tar content, and tar dew point using three different bed materials with softwood as standard fuel and bark

discussed. Table 5 shows the gas cleaning equipment used for the different scenarios.

The considerations leading to the selection of a gas cleaning setup needs to include two main aspects which contradict each other to a certain extent: energetic optimisation vs. maximal reduction of NPE. Figures 5 and 6 show process flow sheets in which the equipment already existent in a pulp and paper mill is displayed in grey colour, whereas the gasification and subsequent gas cleaning are displayed in green colour. Here, the authors assume a paper mill where a biomass boiler for combustion of bark is already installed as a CFB boiler. This is not valid in general but represents a typical modern paper mill. The existing units of the process are not shown in detail. Figure 5 shows the energetically favourable process when focusing on the temperature levels. In this first setup, the particle separation after the gasification reactor is realised by a multistage cyclone. The product gas temperature is regulated to approx. $750{ }^{\circ} \mathrm{C}$ after the multistage cyclone. Therefore, all organic components in the product gas, including higher hydrocarbons-referred to as tar-are burned in the lime kiln. The sensible heat of the product gas with approx. $1550 \mathrm{~kW}$ is comparably high in this configuration. However, no internal energy is transferred to the steam necessary for fluidisation of the gasification reactor because no product gas cooling is installed. Therefore, during the operation of the gasification reactor, externally generated saturated steam needs to be continuously supplied. Furthermore, only a simple particle separation is integrated into the form of a multistage cyclone.

Figure 6 shows the process flow sheet of two other possible configurations, which differ in the temperature level of the product gas filter and the degree of the particle separation compared with Fig. 5. In the second setup, the product gas after the gasification reactor is cooled down to approx. $450{ }^{\circ} \mathrm{C}$. Thus, the tars in the product gas do not yet condensate and are therefore burned in the lime kiln. In this configuration, the sensible heat of the product gas is approx. $767 \mathrm{~kW}$, which is lower in comparison to the first process setup. However, as shown in Fig. 6, energy is transferred from the product gas to the steam supply of the gasification reactor in the product gas heat exchanger. The third setup, also displayed in Fig. 6, is similar to the second one with the difference, that the product gas is cooled down to below $200{ }^{\circ} \mathrm{C}$, so that a conventional fabric particle filter can be used instead of a ceramic filter. In this setup, the sensible heat of the product gas is approx. $340 \mathrm{~kW}$, which is significantly lower than in the first and second setups. In this third process setup, more surplus 
steam is produced in comparison to the second setup, which can be used as a fluidisation agent in the gasification reactor or in a biomass dryer.

Since gasification is realised using steam as a gasifying agent, the product gas has approx. $45-50 \mathrm{Vol} \%$ water content. Furthermore, tar components are present in the product gas. On the one hand, tars, which are organic molecules, contribute to the heating value of the product gas. On the other hand, they can potentially lead to problems in downstream equipment. Condensation of tar leads to either liquid or solid deposition which upon accumulation can result in undesired operation shutdowns. Therefore, as additional gas cleaning step a liquid scrubber unit is considered. As the satisfactory separation of NPE already results from significantly cooling down the product gas including a liquid scrubber unit is a further reasonable step in achieving the condensation of steam and the reduction of tars from the product gas. Figure 7 shows this fourth process setup further elaborating on the gas cleaning. It is noteworthy to mention that in the presented process setups, the gasification route does not produce additional waste streams from the process. Separated particles in the product gas filter, typically referred to as fly char, as well as the emulsion obtained from solving tars in the scrubber, are recirculated to the bark boiler. There, they are burnt and thus inherently disposed of. Only ash from the flue gas filter of the combustion reactor needs to be discharged from the system in the same manner as for direct incineration of biomass.

This product gas cleaning setup of heat exchangers, followed by a fabric filter and a liquid scrubber unit using rapeseed methyl ester as solvent was installed in industrial-scale dual fluidised bed steam gasification plants in Güssing and Oberwart, Austria, as well as in Senden, near Ulm, Germany, with fuel power between 8 and 15 MW [43]. Therefore, it is possible to derive the separation efficiencies for tars and water in the product gas from long-term experience in these industrial plants. Besides, reducing the dust freight the product gas filter also reduces the gravimetric tar content by approx. $80 \%$ and the GC-MS tar content by approx. $34 \%$. The subsequently installed RME scrubber further reduces the remaining tar content by another approx. 50\% [44]. Heavier molecules, referring to tar molecules with a molecular weight of naphthalene or higher, are almost completely separated in the scrubber, whereas the separation efficiency decreases for lighter tar molecules. However, the lighter tar molecules have a higher dew point which significantly decreases the risk for undesired condensation in downstream equipment.

Besides the energetic considerations, the impact of the different particle separation units on the reduction of the NPE in the system needs to be included in the discussion.

Figure 8 shows the separation efficiency of the four scenarios. Scenario 1, based on a multi-cyclone, leads 


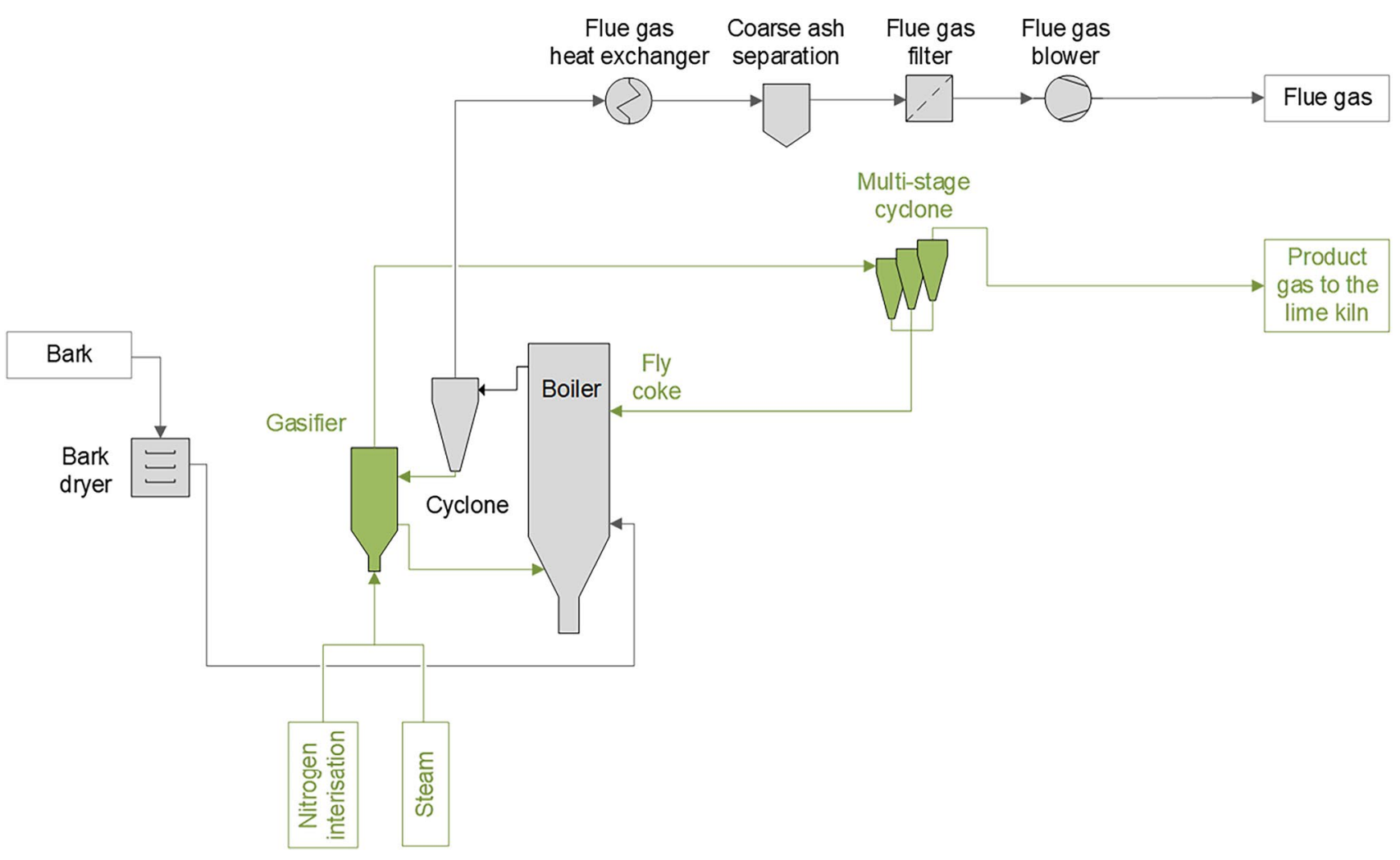

Fig. 5 Simplified flow sheet of process setup with a multistage cyclone for separation of NPE (scenario 1)

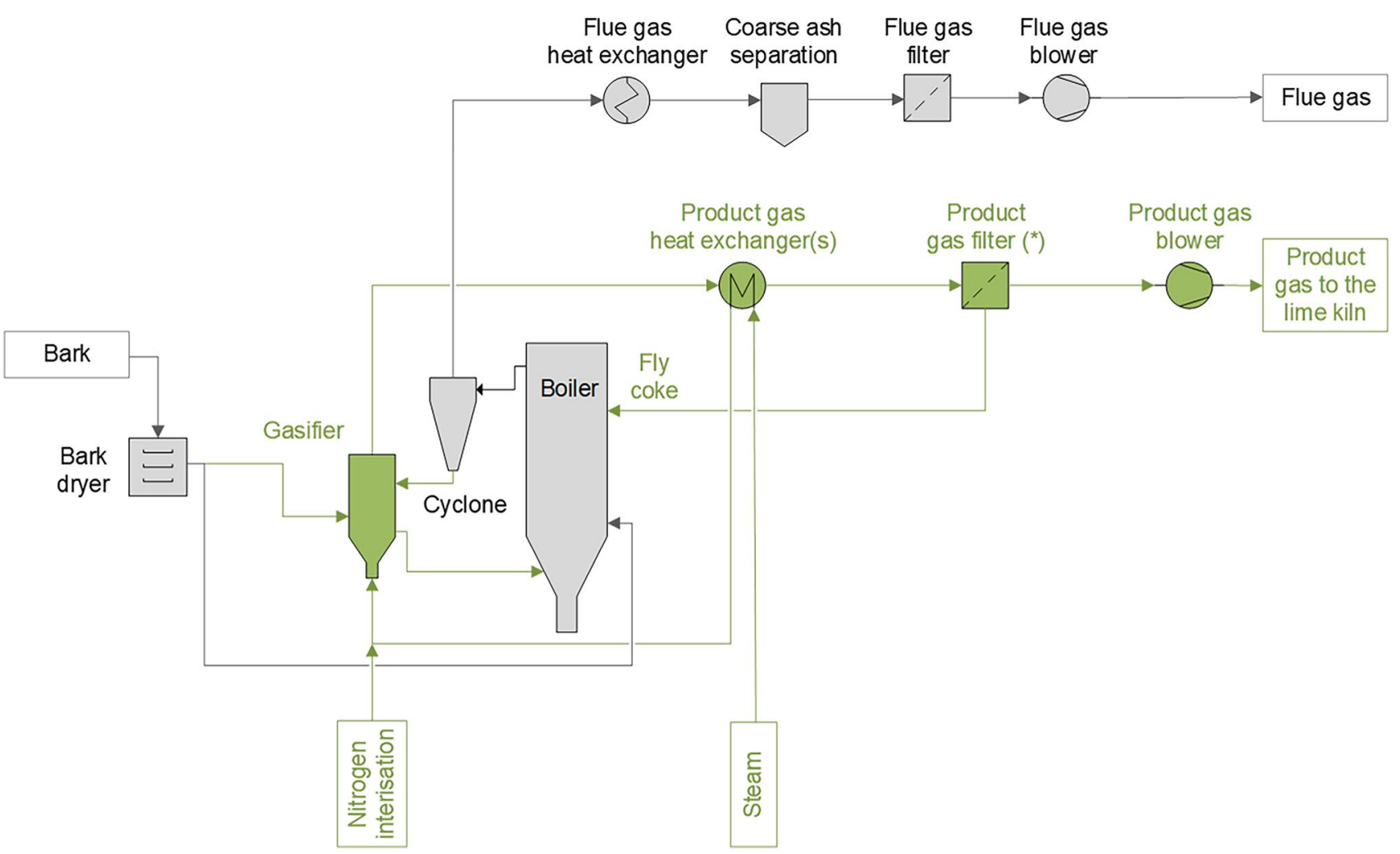

Fig. 6 Simplified flow sheet of process setup with either $(*)$ a ceramic particle filter $\left(450{ }^{\circ} \mathrm{C}\right)$ or a fabric particle filter $\left(<200{ }^{\circ} \mathrm{C}\right)$ for separation of NPE (scenarios 2 and 3) 


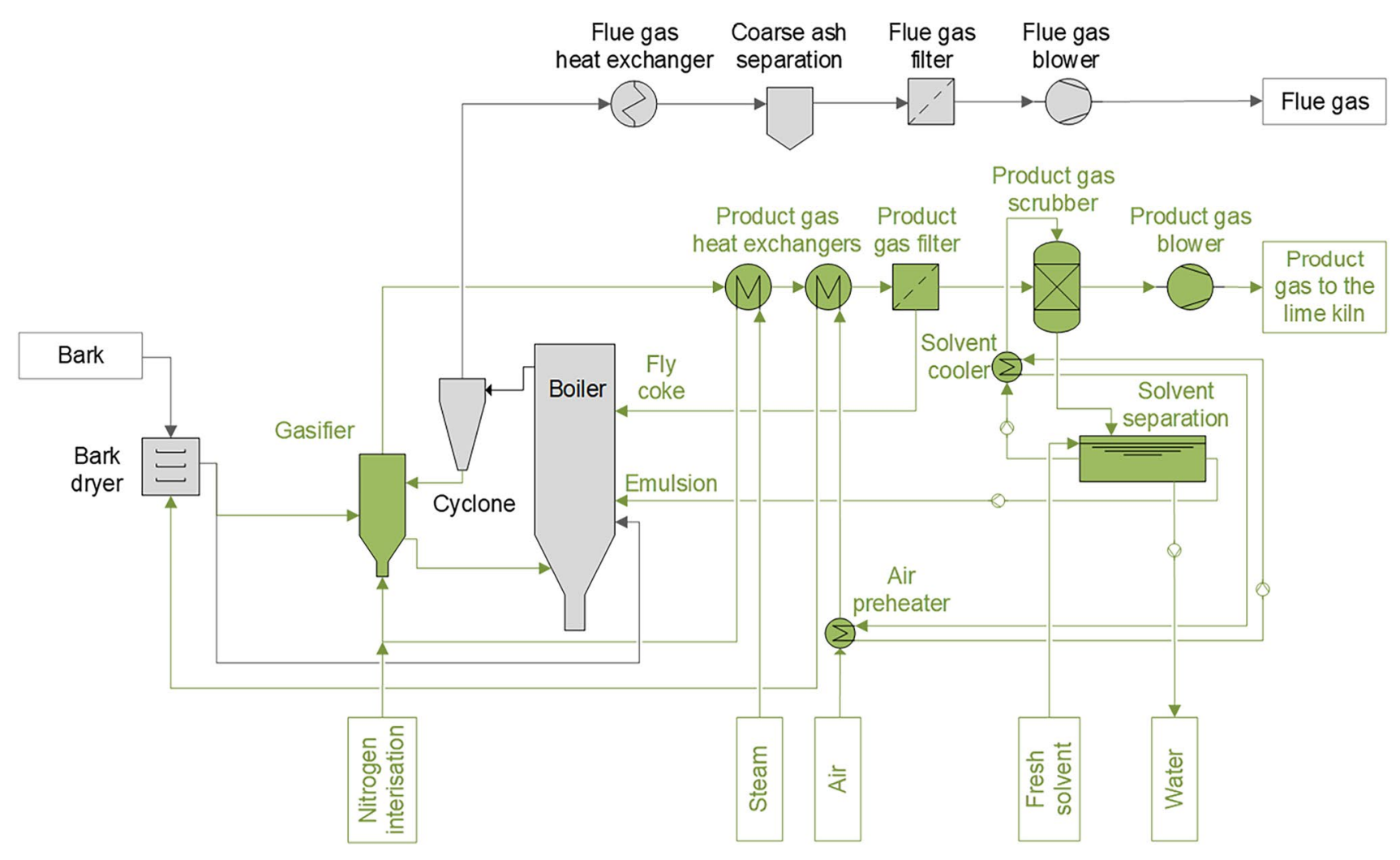

Fig. 7 Simplified flow sheet of process setup with a fabric particle filter $\left(<200{ }^{\circ} \mathrm{C}\right)$ for separation of NPE and a subsequent liquid scrubber unit for the reduction of tars and condensation of steam (scenario 4)

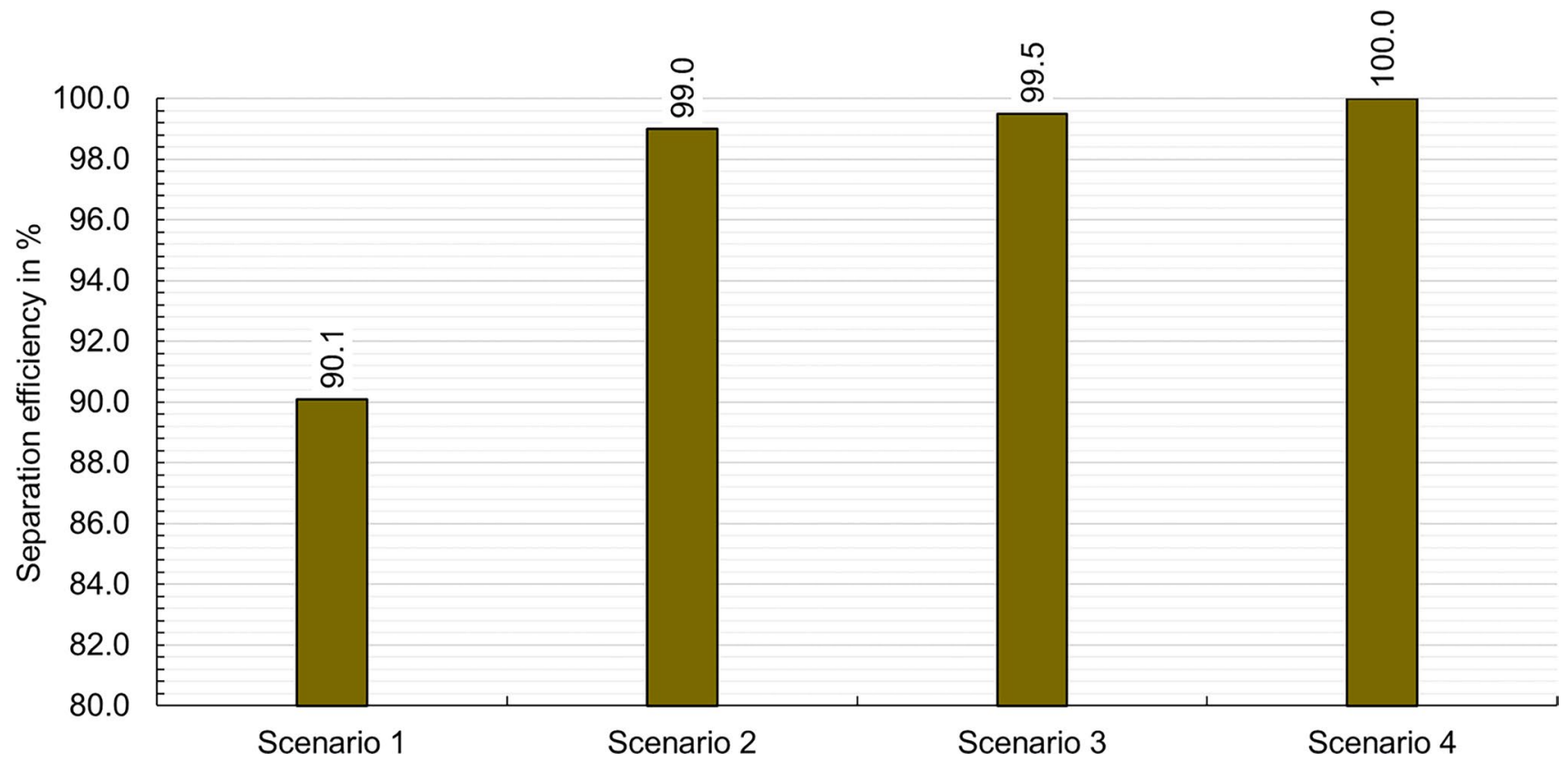

Fig. 8 Separation efficiency of NPE for the four scenarios 


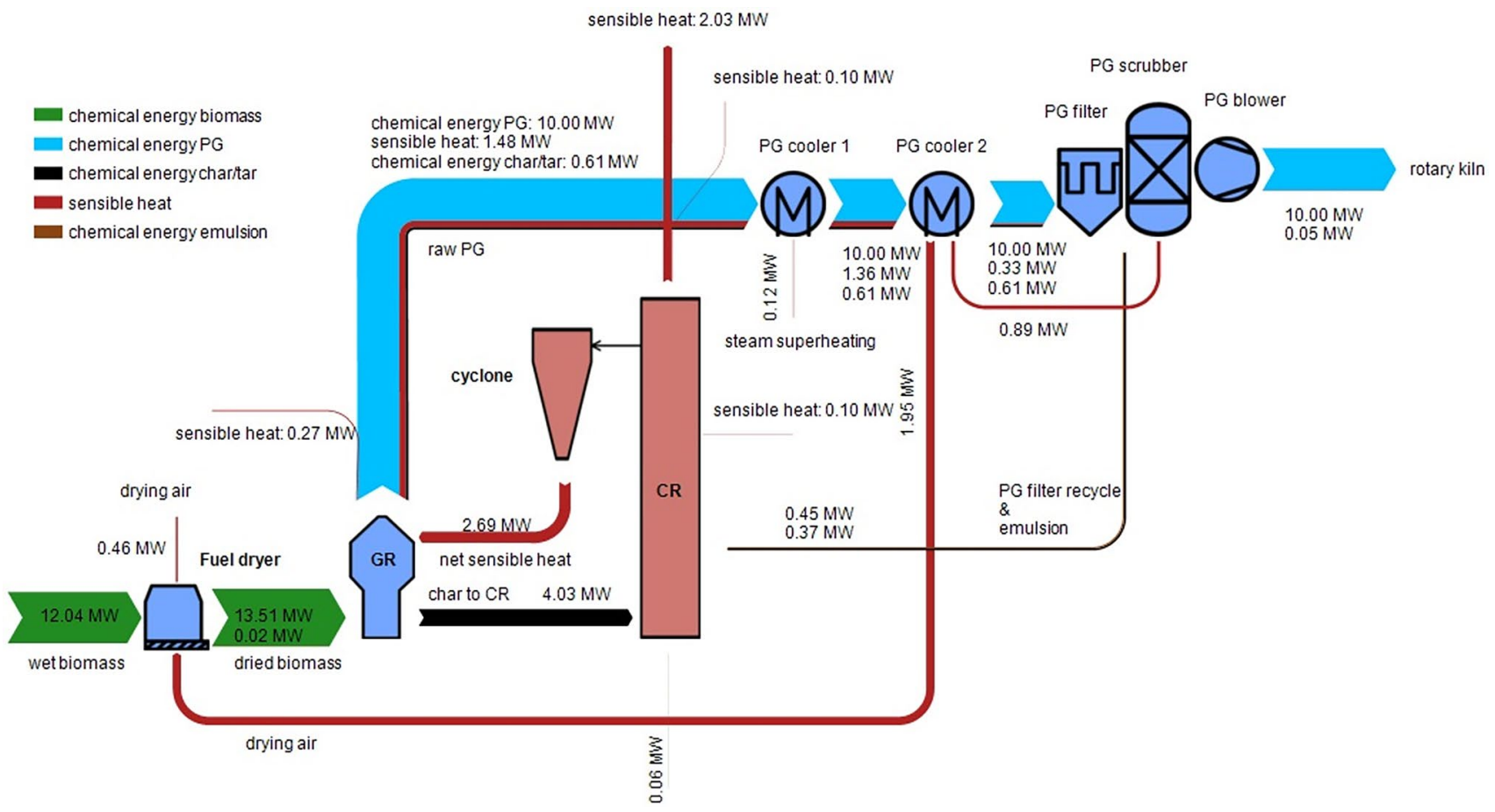

Fig. 9 Mass and energy balance for Scenario 4

Table 6 Comparison of the results between natural gas and product gas combustion obtained from the free-standing experimental test rig

\begin{tabular}{|c|c|c|c|c|c|}
\hline \multirow[b]{2}{*}{ Capacity } & \multirow[b]{2}{*}{$\mathrm{kW}$} & \multicolumn{2}{|c|}{$\begin{array}{l}\text { Natural } \\
\text { gas }\end{array}$} & \multicolumn{2}{|c|}{$\begin{array}{l}\text { Product } \\
\text { gas }\end{array}$} \\
\hline & & 100 & 198 & 105 & 204 \\
\hline Gas flow & $\mathrm{Nm}^{3} / \mathrm{h}$ & 10 & 19.9 & 35.5 & 68.9 \\
\hline Air flow & $\mathrm{Nm}^{3} / \mathrm{h}$ & 98 & 201 & 87 & 161 \\
\hline Flame length & $\mathrm{cm}$ & 70 & 80 & 50 & 50 \\
\hline Maximal temperature burner left & ${ }^{\circ} \mathrm{C}$ & $326^{\mathrm{a}}$ & $296^{\mathrm{a}}$ & $692^{\mathrm{b}}$ & $727^{b}$ \\
\hline $\begin{array}{l}\text { Maximal temperature burner } \\
\text { right }\end{array}$ & ${ }^{\circ} \mathrm{C}$ & $305^{\mathrm{a}}$ & $260^{a}$ & $676^{\mathrm{b}}$ & $739^{b}$ \\
\hline
\end{tabular}

to the introduction of significant amounts of NPE into the lime cycle, as the separation efficiency only reached approx. 90\%. Based on the fact that NPE accumulate in the lime kiln, this scenario needs to be excluded for further considerations. Scenario 2 and 3 result in similar separation efficiencies of $99.0 \%$ and $99.5 \%$, respectively. Regarding particle separation efficiency, these two scenarios can be considered satisfactory in their performance. However, as there is no liquid scrubber installed in either of the setups, the product gas is still containing approx. $50 \%$ of steam, which would be introduced into the gas burner. Therefore, scenario 4 is selected as the most promising process layout, based on its practically complete separation of NPE, scrubbing of tars and condensation of steam in the scrubber.

A complete mass and energy balance for scenario 4 is displayed in Fig. 9.

\subsection{Combustion of product gas as a substitute for natural gas}

Product gas from bark DFB gasification shall be used in the lime kiln, but this product gas shows different
Table 7 Calculated values for the air demand and resulting flue gas stream for combustion of 100-kW natural gas and product gas (with and without pure $\mathrm{O}_{2}$ addition)

\begin{tabular}{llllll}
\hline & Fuel gas stream & $\begin{array}{l}\text { Oxygen content } \\
\text { combustion air }\end{array}$ & Air demand & Oxygen demand & Flue gas stream \\
\hline & $\mathrm{Nm}^{3} / \mathrm{h}$ & $\mathrm{Vol} \%$ & $\mathrm{Nm}^{3} / \mathrm{h}$ & $\mathrm{Nm}^{3} / \mathrm{h}$ & $\mathrm{Nm}^{3} / \mathrm{h}$ \\
Natural gas & 10,03 & $21.0 \%$ & 101.38 & 0.00 & 111.42 \\
Product gas & 33,73 & $21.0 \%$ & 89.57 & 0.00 & 113.78 \\
Product gas & 33,73 & $22.9 \%$ & 79.80 & 1.97 & 105.97 \\
Product gas & 33,73 & $24.8 \%$ & 71.59 & 3.62 & 99.42 \\
\hline
\end{tabular}


Table 8 Results obtained from the experiments using a burner chamber for combustion of natural gas and product gas (with and without pure $\mathrm{O}_{2}$ addition)

\begin{tabular}{|c|c|c|c|c|c|c|c|c|}
\hline & \multirow{3}{*}{$\begin{array}{l}\text { Fuel gas stream } \\
\mathrm{Nm}^{3} / \mathrm{h}\end{array}$} & \multirow{3}{*}{$\begin{array}{l}\text { Oxygen content } \\
\%\end{array}$} & \multicolumn{5}{|c|}{ Wall temperatures $T 1-T 5$} & \multirow{3}{*}{$\begin{array}{l}\text { Ceiling } \\
\text { tempera- } \\
\text { ture } \\
{ }^{\circ} \mathrm{C}\end{array}$} \\
\hline & & & \multicolumn{5}{|l|}{${ }^{\circ} \mathrm{C}$} & \\
\hline & & & $T 1$ & $T 2$ & $T 3$ & $T 4$ & $T 5$ & \\
\hline Natural gas & 11.9 & 21.0 & 1223 & 1251 & 1256 & 1271 & 1285 & 1297 \\
\hline Product gas & 34.0 & 21.0 & 1209 & 1234 & 1238 & 1251 & 1265 & 1277 \\
\hline Product gas & 34.4 & 22.9 & 1214 & 1239 & 1244 & 1259 & 1275 & 1288 \\
\hline Product gas & 34.4 & 24.8 & 1229 & 1254 & 1259 & 1274 & 1289 & 1302 \\
\hline
\end{tabular}

properties from natural gas. Therefore, an experimental study has been carried out in two different burners for comparison of the flames on the one hand of natural gas and on the other hand of product gas from bark gasification.

Table 6 shows the comparison of the results between natural gas and product gas combustion obtained from a free-standing experimental test rig. Two different capacities of approx. $100 \mathrm{~kW}$ and approx. $200 \mathrm{~kW}$ are included in this comparison. One of the main issues with substituting natural gas with product gas from steam gasification is the necessary gas flow to achieve the same capacity in the burner. Due to the lower heating value of the product gas in comparison to natural gas, a higher gas flow of fuel gas is necessary. As shown in Table 7, the flue gas stream after the lime kiln is slightly increased when product gas is used as the necessary airflow for combustion is lower in comparison to the natural gas. By enrichment with pure $\mathrm{O}_{2}$ in the gas burner - which has also an impact on the combustion temperature as discussed further below - the flue gas stream can be decreased which leads to a relief (or downsizing) of the gas treatment downstream. The obtained results are in good correlation with previous experience from gas burner experiments [45-47].

Furthermore, due to the high $\mathrm{H}_{2}$ content in the product gas, the ignition of the gas occurs earlier than is the case for natural gas. Therefore, the temperature in the burner itself is significantly increased from $260-326{ }^{\circ} \mathrm{C}$ when natural gas is used to $676-739{ }^{\circ} \mathrm{C}$ when product gas is used. Also, the flame length is decreased from $70-80 \mathrm{~cm}$ in the case of natural gas to $50 \mathrm{~cm}$ in the case of product gas. However, it is noteworthy to consider, that the experiments were conducted using a natural gas/air burner with a ceramic tube for natural gas without adapting it by any means. The results therefore do not show a problem using product gas but elaborate on the different ignition characteristics resulting from the gas composition. This merely shows the necessity to e.g. adapt the gas flow in the burner by design changes. Using a respective gas burner would alleviate these observations.

${ }^{a}$ Highest temperature measured at the exit of the burner.
${ }^{b}$ Highest temperature measured at the middle of the burner.

Table 8 shows the results obtained from the experiments using a burner chamber. The oxygen content in the table refers to the oxygen content of the combustion air. Thus, some of the combustion air was replaced with pure oxygen to achieve 23 and $25 \%$ oxygen in the combustion air, respectively. The measured wall temperatures (T1-T5) indicated that the combustion of product gas resulted in lower temperatures inside the burner chamber. Also, the ceiling temperature was approx. $20{ }^{\circ} \mathrm{C}$ lower in the case of product gas combustion in comparison to natural gas combustion. Adding 2\% pure oxygen increased the temperatures to a level slightly beneath that of natural gas. Increasing the amount of pure oxygen from 2 to $4 \%$ led to a further temperature increase resulting in temperature levels above that of natural gas. Thus, using the identical setup for both the combustion of natural gas and product gas leads to slightly different temperatures inside the burner chamber, which can be equalised out by the addition of pure oxygen.

\section{Conclusions}

Steam gasification of bark is suitable to produce a gas of medium calorific value as substitution of natural gas in the lime kiln. The integration into a pulp and paper mill can be performed by turning an existing CFB bark boiler into a DFB steam gasification plant. The configuration of the gas cleaning needs to be adapted according to the sensitivity and requirements of the chemical recovery process. In a process with a high degree of closure, it is advised to rely on a gas cleaning setup involving heat exchangers, a fabric particle filter, and a liquid scrubber unit. Thus, NPE can be satisfyingly separated from the gas stream to avoid accumulation in the system. Furthermore, the scrubber reduces the water and tar content to avoid undesired condensation. The gas flow of product gas into the gas burner is increased by a factor of approx. 3 due to the lower heating value of the product gas in comparison with natural gas. Adaptions of the burner 
itself are advised, as the ignition of the $\mathrm{H}_{2}$-rich product gas occurs earlier than it does for natural gas.

The present study has shown great potential for the integration of steam gasification into the pulp and paper industry.

Acknowledgements This study was carried out within the BESTBioenergy and Sustainable Technologies GmbH project C-20-075-0. BEST-Bioenergy and Sustainable Technologies $\mathrm{GmbH}$ is funded within the Austrian COMET programme, which is managed by the Austrian Research Promotion Agency (FFG) and promoted by the Federal Government of Austria as well as the federal states of Vienna, Lower Austria, and Styria. We are grateful for the support of our scientific partner, the Institute of Chemical, Environmental and Bioscience Engineering at TU Wien. Furthermore, we want to express our thanks to the team of Messer Austria $\mathrm{GmbH}$, who contributed greatly to this work in the frame of the gas burner test.

Funding Open access funding provided by TU Wien (TUW).

\section{Declarations}

Competing interests The authors declare no competing interests.

Open Access This article is licensed under a Creative Commons Attribution 4.0 International License, which permits use, sharing, adaptation, distribution and reproduction in any medium or format, as long as you give appropriate credit to the original author(s) and the source, provide a link to the Creative Commons licence, and indicate if changes were made. The images or other third party material in this article are included in the article's Creative Commons licence, unless indicated otherwise in a credit line to the material. If material is not included in the article's Creative Commons licence and your intended use is not permitted by statutory regulation or exceeds the permitted use, you will need to obtain permission directly from the copyright holder. To view a copy of this licence, visit http://creativecommons. org/licenses/by/4.0/.

\section{References}

1. Magnusson H. From recovery boiler to integration of a textile fiber plant combination of mass balance analysis and chemical engineering From recovery boiler to integration of a textile fiber plant. 2015.

2. Ek, M.; Gellerstedt, G.; Henriksson G. Pulp and Paper Chemistry and Technology Volume 2. vol. 2. Walter de Gruyter GmbH \& Co. KG; 2009.

3. Bajpai P. Biermann's Handbook of Pulp and Paper. 3rd ed. Elsevier; 2018.

4. Bajpai P. Pulp and Paper Industry: Chemical Recovery. 1st ed. Elsevier; 2016.

5. Manskinen K, Nurmesniemi H, Pöykiö R (2011) Total and extractable non-process elements in green liquor dregs from the chemical recovery circuit of a semi-chemical pulp mill. Chem Eng J 166:954-961. https://doi.org/10.1016/j.cej.2010.11.082

6. Ulmgren P (1997) Non-process elements in a bleached kraft pulp mill with a high degree of system closure - state of the art. Nord Pulp Pap Res J 12:32-40. https://doi.org/10.3183/ npprj-1997-12-01-p032-041
7. Eriksson M, Carlborg M, Broström M (2019) Characterization of ring deposits inside a quicklime producing long rotary kiln. Energy Fuels 33(11731):11740. https://doi.org/10.1021/acs.energ yfuels.9b00865

8. Kuparinen K, Vakkilainen E (2017) Green pulp mill: renewable alternatives to fossil fuels in lime kiln operations. BioResources 12:4031-48. https://doi.org/10.15376/biores.12.2.4031-4048

9. Francey S, Tran H, Jones A (2009) Current status of alternative fuel use in lime kilns. Tappi J 19:370

10. Bajpai P. Green chemistry and sustainability in pulp and paper industry. Springer International Publishing; 2015. https://doi. org/10.1007/978-3-319-18744-0.

11. Bergquist AK, Söderholm K (2016) Sustainable energy transition: the case of the Swedish pulp and paper industry 19731990. Energy Effic 9:1179-1192. https://doi.org/10.1007/ s12053-015-9416-5

12. Pio DT, Tarelho LAC, Pinto PCR (2020) Gasification-based biorefinery integration in the pulp and paper industry: a critical review. Renew Sustain Energy Rev 133:110210. https://doi.org/ 10.1016/j.rser.2020.110210

13. Mishra S, Upadhyay RK (2021) Review on biomass gasification: gasifiers, gasifying mediums, and operational parameters. Mater Sci Energy Technol 4:329-340. https://doi.org/10.1016/J. MSET.2021.08.009

14. Hanchate N, Ramani S, Mathpati CS, Dalvi VH (2021) Biomass gasification using dual fluidized bed gasification systems: a review. J Clean Prod 280:123148. https://doi.org/10.1016/J. JCLEPRO.2020.123148

15. Hofbauer H, Rauch R, Loeffler G, Kaiser S, Fercher E, Tremmel H. Six years experience with the FICFB-gasification process. Proc. 12th Eur. Conf. Technol. Exhib. Biomass Energy, Ind. Clim. Prot., Amsterdam, The Netherlands: 2002, p. 982-985.

16. Benedikt F, Fuchs J, Schmid JC, Müller S, Hofbauer H (2017) Advanced dual fluidized bed steam gasification of wood and lignite with calcite as bed material. Korean J Chem Eng 34:25482558. https://doi.org/10.1007/s11814-017-0141-y

17. Boström D, Skoglund N, Grimm A, Boman C, Öhman M, Broström M et al (2011) Ash transformation chemistry during combustion of biomass. Energy Fuels 26:85-93. https://doi.org/10. 1021/ef201205b

18. Berdugo Vilches T, Maric J, Knutsson P, Rosenfeld DC, Thunman H, Seemann M (2018) Bed material as a catalyst for char gasification: the case of ash-coated olivine activated by $\mathrm{K}$ and S addition. Fuel 224:85-93. https://doi.org/10.1016/j.fuel.2018. 03.079

19. Kirnbauer F, Wilk V, Kitzler H, Kern S, Hofbauer H (2012) The positive effects of bed material coating on tar reduction in a dual fluidized bed gasifier. Fuel 95:553-562

20. Kuba M, Havlik F, Kirnbauer F, Hofbauer H (2015) Influence of bed material coatings on the water-gas-shift reaction and steam reforming of toluene as tar model compound of biomass gasification. Biomass Bioenerg 89:40-49. https://doi.org/10.1016/j.biomb ioe.2015.11.029

21. Kuba M, Kirnbauer F, Hofbauer H (2017) Influence of coated olivine on the conversion of intermediate products from decomposition of biomass tars during gasification. Biomass Convers Biorefinery 7:11-21. https://doi.org/10.1007/s13399-016-0204-z

22. Kuba M, Fürsatz K, Janisch D, Aziaba K, Chlebda D, Łojewska $\mathrm{J}$, et al. Surface characterization of ash-layered olivine from fluidized bed biomass gasification. Biomass Convers Biorefinery 2020:1-10. https://doi.org/10.1007/s13399-020-00863-2.

23. Fürsatz K, Fuchs J, Benedikt F, Kuba M, Hofbauer H (2021) Effect of biomass fuel ash and bed material on the product gas composition in DFB steam gasification. Energy 219:119650. https://doi.org/10.1016/j.energy.2020.119650 
24. Wetterlund E, Pettersson K, Harvey S (2011) Systems analysis of integrating biomass gasification with pulp and paper production effects on economic performance, $\mathrm{CO} 2$ emissions and energy use. Energy 36:932-941. https://doi.org/10.1016/j.energy.2010.12.017

25. Schmid JC, Benedikt F, Fuchs J, Mauerhofer AM, Müller S, Hofbauer H. Syngas for biorefineries from thermochemical gasification of lignocellulosic fuels and residues -5 years' experience with an advanced dual fluidized bed gasifier design. Biomass Convers Biorefinery 2019:1-38. https://doi.org/10.1007/ s13399-019-00486-2.

26. Naqvi M, Yan J, Dahlquist E (2010) Black liquor gasification integrated in pulp and paper mills: a critical review. Bioresour Technol 101:8001-8015. https://doi.org/10.1016/j.biortech.2010. 05.013

27. Larson ED, Consonni S, Katofsky RE, Consulting N, Iisa K, Frederick WJ. A Cost-benefit assessment of gasification-based biorefining in the kraft pulp and paper industry Volume 1 Main Report. vol. 1. Pittsburgh, PA, and Morgantown, WV: 2006. https://doi. org/10.2172/912520.

28. Consonni S, Katofsky RE, Larson ED (2009) A gasification-based biorefinery for the pulp and paper industry. Chem Eng Res Des 87:1293-1317. https://doi.org/10.1016/j.cherd.2009.07.017

29. Wiinikka H, Johansson AC, Wennebro J, Carlsson P, Öhrman OGW (2015) Evaluation of black liquor gasification intended for synthetic fuel or power production. Fuel Process Technol 139:216-225. https://doi.org/10.1016/J.FUPROC.2015.06.050

30. Dahlquist E, Naqvi M, Thorin E, Yan J, Kyprianidis K, Hartwell $P$ (2017) Experimental and numerical investigation of pellet and black liquor gasification for polygeneration plant. Appl Energy 204:1055-1064. https://doi.org/10.1016/J.APENERGY.2017.05. 008

31. Akbari M, Oyedun AO, Kumar A (2018) Ammonia production from black liquor gasification and co-gasification with pulp and waste sludges: a techno-economic assessment. Energy 151:133143. https://doi.org/10.1016/J.ENERGY.2018.03.056

32. Thunman H, Seemann M, Berdugo Vilches T, Maric J, Pallares D, Ström H et al (2018) Advanced biofuel production via gasification - lessons learned from 200 man-years of research activity with Chalmers' research gasifier and the GoBiGas demonstration plant. Energy Sci Eng 6:6-34. https://doi.org/10.1002/ese3.188

33. Benedikt F, Schmid JC, Fuchs J, Mauerhofer AM, Müller S, Hofbauer H (2018) Fuel flexible gasification with an advanced $100 \mathrm{~kW}$ dual fluidized bed steam gasification pilot plant. Energy 164:329-343. https://doi.org/10.1016/j.energy.2018.08.146

34. Wagner K, Häggström G, Skoglund N, Priscak J, Kuba M, Öhman $M$ et al (2019) Layer formation mechanism of K-feldspar in bubbling fluidized bed combustion of phosphorus-lean and phosphorus-rich residual biomass. Appl Energy 248:545-554. https://doi. org/10.1016/j.apenergy.2019.04.112

35. Ahlström JM, Alamia A, Larsson A, Breitholtz C, Harvey S, Thunman H (2019) Bark as feedstock for dual fluidized bed gasifiers-operability, efficiency, and economics. Int J Energy Res 43:1171-1190. https://doi.org/10.1002/er.4349

36. Schmid JC, Pfeifer C, Kitzler H, Pröll T, Hofbauer H. A new dual fluidized bed gasifier design for improved in situ conversion of hydrocarbons. Proc. Int. Conf. Polygeneration Strateg., Vienna, Austria: 2011, p. 1-10.

37. Kuba M, Kraft S, Kirnbauer F, Maierhans F, Hofbauer H (2018) Influence of controlled handling of solid inorganic materials and design changes on the product gas quality in dual fluid bed gasification of woody biomass. Appl Energy 210:230-240. https://doi. org/10.1016/j.apenergy.2017.11.028

38. Wilk V, Hofbauer H (2016) Analysis of optimization potential in commercial biomass gasification plants using process simulation. Fuel Process Technol 141:138-147. https://doi.org/10.1016/j. fuproc.2015.07.035

39. Mauerhofer AM, Schmid JC, Benedikt F, Fuchs J, Müller S, Hofbauer H (2019) Dual fluidized bed steam gasification: change of product gas quality along the reactor height. Energy 173:12561272. https://doi.org/10.1016/j.energy.2019.02.025

40. Weber G, Di GA, Rauch R, Hofbauer H (2016) Developing a simulation model for a mixed alcohol synthesis reactor and validation of experimental data in \{IPSE\} pro. Fuel Process Technol 141:167-176

41. Pröll T, Hofbauer H. Development and application of a simulation tool for biomass gasification based processes. Int J Chem React Eng 2008;6. https://doi.org/10.2202/1542-6580.1769.

42. Mayr B, Prieler R, Demuth M, Potesser M, Hochenauer C (2017) Computational analysis of a semi-industrial furnace fired by a flat flame burner under different $\mathrm{O} 2 / \mathrm{N} 2$ ratios using the steady laminar flamelet approach. J Energy Inst 90:602-612. https://doi.org/10. 1016/j.joei.2016.05.002

43. Larsson A, Kuba M, Berdugo Vilches T, Seemann M, Hofbauer H, Thunman H. Steam gasification of biomass - typical gas quality and operational strategies derived from industrial-scale plants. Fuel Process Technol 2021;212. https://doi.org/10.1016/j.fuproc. 2020.106609.

44. Bardolf R. Optimierung eines Produktgaswäschers bei der Biomassedampfvergasung im Zweibettwirbelschichtverfahren. (2017) TU Wien, Doctoral Thesis, Library ID: AC14523525

45. Prieler R, Bělohradský P, Mayr B, Demuth M, Hochenauer C. Numerical modeling of oxygen enhanced combustion and transient heating characteristics in a reheating furnace. Proc Aust Combust Symp 2015:3-6.

46. Prieler R, Mayr B, Demuth M, Spoljaric D, Hochenauer C (2015) Application of the steady flamelet model on a lab-scale and an industrial furnace for different oxygen concentrations. Energy 91:451-464. https://doi.org/10.1016/j.energy.2015.08.070

47. Mayr B, Prieler R, Demuth M, Potesser M, Hochenauer C (2015) CFD and experimental analysis of a $115 \mathrm{~kW}$ natural gas fired lab-scale furnace under oxy-fuel and air-fuel conditions. Fuel 159:864-875. https://doi.org/10.1016/j.fuel.2015.07.051

Publisher's Note Springer Nature remains neutral with regard to jurisdictional claims in published maps and institutional affiliations. 